\title{
Mental Health and Justice System Involvement: A Conceptual Analysis of the
}

\section{Literature}

\author{
McCormick, Sarah., Peterson-Badali, Michele., Skilling, Tracey. \\ Version Post-print/accepted manuscript \\ Citation Mental health and justice system involvement: A conceptual analysis \\ of the literature. McCormick, Sarah; Peterson-Badali, Michele; \\ Skilling, Tracey A. Psychology, Public Policy, and Law, Vol 21(2), \\ May 2015, 213-225. \\ DOI http://dx.doi.org/10.1037/law0000033
}

Publisher statement: This article may not exactly replicate the final version published in the APA journal. It is not the copy of record. 
Running head: MENTAL HEALTH AND JUSTICE SYSTEM INVOLVEMENT

Mental health and justice system involvement: A conceptual analysis of the literature

\author{
Sarah McCormick ${ }^{a}$ \\ Michele Peterson-Badali ${ }^{a}$ \\ Tracey A. Skilling ${ }^{b}$
}

Department of Applied Psychology \& Human Development, Ontario Institute for Studies in Education, University of Toronto, Toronto, ON, Canada ${ }^{a}$, Child, Youth \& Family Program, Centre for Addiction and Mental Health, Toronto, ON, Canada ${ }^{b}$

Author Note

Correspondence concerning this article should be addressed to Michele Peterson-Badali, Department of Applied Psychology \& Human Development, Ontario Institute for Studies in Education, University of Toronto, 252 Bloor Street West, $9^{\text {th }}$ floor, Toronto, ON, Canada, M5S 1V6. Email: m.petersonbadali@utoronto.ca 


\begin{abstract}
The fact that individuals with mental health problems are significantly overrepresented in the justice system is a significant concern for public policy and practice. Psychology research examining mental health and risk for criminal offending can be broadly categorized into two approaches that have remained either independent of one another or in apparent conflict: the first based in clinical literature and focused on associations with psychopathology, and the second focused on forensic rehabilitation (e.g., represented in the Risk-Need-Responsivity literature). Although the policy and practice goals associated with these literatures are not synonymous, they overlap in critical respects. The lack of dialogue between the two approaches impoverishes both and contributes to misunderstanding that undermines effective policymaking and practice. To facilitate interpretation of these two approaches, in the current paper research examining mental health issues in justice-involved adults and youth is critically analyzed in terms of differing goals, implicit assumptions, intended scope of the literature, and key terminology (especially definitions of "mental health" problems and of "risk"). These differences are clarified to identify areas of congruence as well as outstanding conflicts. Suggestions are presented for future research at the nexus of these two approaches, which would serve the goal of developing evidence-informed policy and practice to reduce recidivism and improve mental health functioning in individuals with mental health problems who are involved in the justice system.
\end{abstract}

Keywords: mental health; justice system; psychopathology; risk-need-responsivity; policy 


\section{Background and outline of the current paper}

The prevalence of mental health concerns is much higher among individuals involved in the criminal justice system than in the general population (Teplin, 1990; Teplin, 1994), a finding that also holds true for justice-involved youth (Chitsabesan \& Bailey, 2006). Previous studies report that the prevalence of mental health difficulties amongst young offenders is comparable to the rate found in youth receiving community mental health services (Atkins et al., 1999) and greatly exceeds the prevalence in the general population. Studies have found that more than $90 \%$ of justice-involved youth meet minimal diagnostic criteria for at least one disorder (Drerup, Croysdale, \& Hoffmann, 2008; Unruh, Gau, \& Waintrup, 2009), and rates of serious mental disorder have been estimated at one in four justice-involved youth (Shufelt \& Cocozza, 2006). In a review of the literature, Vermeiren (2003) found prevalence rates of any mental disorder ranging from $50 \%$ to $100 \%$ amongst justice-involved youth in studies sampled.

These statistics raise significant concerns for research, frontline practice, and policymakers. Questions have included: Why these rates are so high? What is the nature of the relationship between offending and mental health functioning? What are appropriate responses at a systemic level? Before identifying possible targets for policy and systems change, we must consider what is meant by responding. Are the goals of intervention - including policy measures and day-to-day front-line practice - the reduction of suffering, reduction of recidivism, or both? And then, what does the literature say in terms of defining the parameters for consideration and the evidence base? Unfortunately, as Myers and Farrell (2008) observed, "Policymakers looking to make informed decisions... are confronted with copious, disjointed research, limited resources, and conflicting agendas (p. 1172)." The fractured state of the current literature poses an immediate challenge to answering these foundational questions. 
To begin to address this challenge, in this paper, we take a 'step back' to examine critical aspects of the two major psychology-based approaches to understanding mental health in the context of the justice system. We aim to address not only content (i.e., study findings) but also and to a larger degree - meta-level questions that facilitate interpretation of the relationship between mental health issues and justice system involvement, including: how has the issue been approached in research, and by whom; how have the different conclusions been reached; and how can dialogue advance to meaningfully inform research, practice and policy? In so doing, our goal is to provide a framework that will serve as a guide to understanding and critically analyzing the existing literature, which is necessary if the literature is be used to meaningfully inform future research, policy, and practice. It should be noted that, while we pose questions of broad relevance for justice-involved populations, much of the literature focuses specifically on youth, whose mental health issues differ in some significant ways from those of adults.

\section{Psychopathology perspective}

Much of the literature examining the connection between mental health and judicial involvement does not represent a self-identified strain of research with an explicit theoretical model. However, what we are calling the 'psychopathology perspective' can be inferred from a common interest in the prevalence of mental health difficulties in justice populations, the association with offending outcomes, and calls for treatment that implicitly assume that: mental health variables are meaningfully related to offending, are therefore useful predictors of offending and should be treated in order to improve outcomes, including reduced recidivism. On the basis of high prevalence rates of mental health concerns within justice-involved populations, these authors have spoken of mental health as a risk factor within a psychopathological model of vulnerability (e.g., Abrantes, Hoffmann, Anton, \& Estroff, 2004). Studies within this category 
are heterogeneous, with contributors representing a range of disciplines including medicine (psychiatry, pediatrics), psychology, nursing, and public health. Where mental health has been construed as a major contributor to offending, intervention has focused on addressing these concerns in order to reduce recidivism. Accordingly, programs have been designed or advocated to address mental health problems in correctional settings. Offenders may be referred to mental health counseling or even processed through specialized mental health courts if they have a mental health problem that is perceived to be significant. For the purposes of this paper, we will focus primarily on the clinical literature that has identified and sought to respond to the mental health burden in the justice system, and the associated calls for system and policy responses.

\section{RNR perspective}

The second literature that has addressed the role of mental health in offending has focused on criminal rehabilitation. This literature broadly includes several approaches, such as the strengths-based Good Lives Model (GLM, Ward \& Stewart, 2003; Robertson, Barnao, \& Ward, 2011), and models that place an emphasis on the therapeutic role of the justice system (e.g., therapeutic jurisprudence approaches, Winick \& Wexler, 2003). We will focus here on the Risk-Need-Responsivity (RNR) model, an evidence-based framework for the assessment and treatment of offenders that has been widely adopted in correctional and community settings. It is based on social learning and personality models of psychology (Andrews \& Bonta, 2010a), which represent a focus on proximate, individual-level risk factors for criminal behavior (Andrews, Bonta, \& Hoge, 1990; Andrews \& Bonta, 2010; Dowden \& Andrews, 1999) and has a stated goal of reducing re-offending. The risk principle states that future offending can be predicted from the offender's level of risk. Implicated in this principle is the need to match the intensity of services to the assessed risk level (i.e., to reserve high intensity treatments for high 
risk cases; Andrews \& Bonta, 2010). The need principle defines criminogenic needs as factors empirically shown to relate directly to offending behavior and differentiates static needs that cannot be changed from dynamic needs that are amenable to change, such as antisocial attitudes, peer affiliates, and parental monitoring. The need principle states that dynamic criminogenic needs should be targeted as intermediate treatment goals (Gendreau, Little, \& Goggin, 1996). The responsivity principle states that intervention should be matched to offenders' learning styles and abilities and be responsive to issues that may moderate an individual's response to treatment, such as reasoning skills (Andrews \& Bonta, 2010).

In recent years, there have been a handful of papers in which authors acknowledge the contributions of both the RNR and psychopathology-based literatures, or some aspects thereof (e.g., Grieger \& Hosser, 2012). Overall, however, there is little communication between these two approaches so research has not benefitted from a sharing of results and conceptualizations. Without a framework with which to critically appraise these literatures and an understanding of their respective contributions, their use of similar-sounding terms may obscure important differences in the issues investigated and hence in what conclusions are warranted.

\section{Understanding differences}

In order to understand why mental health has been characterized as a risk factor for justice system involvement by the psychopathology literature and not by the RNR literature, it is necessary to review what has informed their respective conclusions. We argue that the two literatures broadly differ in seven important aspects: (1) the major goals; (2) definition of risk; (3) predictors of interest; (4) outcomes of interest; (5) timelines of interest; (6) features- versus disorders- based approaches; and (7) what is included in the category of "mental health" 
concerns (although not all of these distinctions will be applicable to every paper, especially in the case of the more diverse psychopathology literature).

\section{(1) The major goals}

The literatures differ in their broad goals, from a primary emphasis on treatment and management of mental health on the part of the psychopathology-oriented authors to the RNR authors' interest in prediction and intervention for the justice system. This distinction is based on a comparison of the explicit frame of the RNR literature and the implicit goals of the psychopathology literature as inferred from dominant themes discussed by representative authors. The authors of the RNR model have clearly identified reduced recidivism as the major organizing goal, from which indications for assessment, management, and correctional policy flow. The psychopathology-based literature has advocated for a broader set of targets including treatment and management of mental health issues. For example, following a major review and meta-analysis of the highly disproportionate prevalence of mental disorders amongst justiceinvolved youth, Fazel, Doll, and Långström (2008) concluded that, "As delinquent adolescents often come from deprived backgrounds with little access to and use of health care in the community, opportunities for intervention in juvenile justice have the potential to make a significant impact [in] public health terms (p. 1017)." Some of the commonly identified goals of this literature include:

- Raising awareness of mental health issues in justice-involved populations by documenting prevalence rates and the extent of the challenge (e.g., Abram et al., 2004; Abram, Paskar, Washburn, \& Teplin, 2008; Abrantes, Hoffmann, \& Anton, 2005; Drerup et al., 2008; Kenny, Lennings, \& Nelson, 2007; Teplin, Abram, McClelland, Dulcan, \& Mericle, 2002). 
- Reducing justice system involvement of individuals with mental illness, especially through advocacy for systems change, diversion, and specialized intervention for offenders with mental illness (e.g., Erickson, 2012; see also reviews in Hartford, Carey, \& Mendonca, 2006; Grudzinskas, Clayfield, Roy-Bujnowski, Fisher, \& Richardson, 2005).

- Accounting for the role of mental health problems in sentencing through legal consideration that may include a sentence of lower severity or that includes mandated therapeutic intervention, possibly through diversion to specialized courts (e.g., Grudzinskas et al., 2005); a related literature has explored how the justice system might be organized to improve outcomes for individuals with mental health problems (e.g., Winick \& Wexler, 2003; see also literature on therapeutic jurisprudence).

- Improving screening, service availability, and service delivery due to concern that individuals with mental illness do not receive needed services (e.g., Kenny et al., 2007; Teplin, Abram, McClelland, Washburn, \& Pikus, 2005), and that screening is important to identify problems and to inform referrals, treatment planning, and service availability (Drerup et al., 2008; Wasserman, McReynolds, Schwalbe, Keating, \& Jones, 2010).

- Improving correctional environment by targeting the organization and set-up of facilities, staff characteristics, and offender management issues, especially in custodial settings (e.g., Cesaroni \& Peterson-Badali, 2013; Liebling \& Maruna, 2005).

\section{(2) The definition of risk}

In the RNR literature, risk factors are "personal attributes and circumstances that are assessable prior to service and are predictive of future criminal behavior" (Andrews et al., 1990, p. 24); they have a direct effect on the likelihood of re-offense. The RNR framework is focused on predictive models and on unique predictors. Several meta-analyses comprehensively address 


\section{TSpace Research Repository}

tspace.library.utoronto.ca

the role of mental health in offending, including the question of its contribution to prediction of recidivism (see Bonta, Law, \& Hanson, 1998; Lipsey \& Derzon, 1998; Douglas, Guy, \& Hart, 2009; Cottle, Lee, \& Heilbrun, 2001). In the RNR lexicon, mental health is not described as a risk factor because it has not been found to significantly predict future offending (although it may share variance with other variables). Rather, it is classified as a responsivity consideration. For example, depression may interfere with a youth's engagement in a treatment program but would not be expected to directly affect the likelihood of that youth offending again in the future.

The term 'risk' is used more broadly in the psychopathology literature. In risk factor research, the first and most basic level involves description of simple associations between two variables (Kazdin, Kraemer, Kessler, Kupfer, \& Offord, 1997; Perkins \& Borden, 2003). While research in the broader field of psychopathology has progressed to more nuanced models, in the area of mental health and justice it is still common to find connections made on the basis of measures of association that reflect this initial stage of research (e.g., Goldstein et al., 2005; Mallett, 2013). For instance, research has found evidence of high levels of psychiatric morbidity amongst incarcerated adolescents and found that these levels were significantly higher than amongst a community, non-mental health sample. On this basis, authors have inferred that psychiatric morbidity might contribute to offending and is therefore a risk factor for judicial involvement. For example, in a highly-cited study, Ulzen and Hamilton (1998) concluded that, "The overwhelming prevalence of multiple psychiatric disorders should guide policy toward optimal allocation of resources to psychiatric treatment, despite the fact that these adolescents are ostensibly held for correction of behaviors" (p. 60). ${ }^{1}$ Similarly, on the basis of a prospective, longitudinal, community-based study that found a relationship between childhood psychiatric disorder and young adult arrests, Copeland, Miller-Johnson, Keeler, Angold, and Costello (2007, 


\section{TSpace Research Repository}

tspace.library.utoronto.ca

p. 1674) argued that, "if childhood psychiatric status is, as this study suggests, a common risk factor for criminality, effective treatment for childhood psychiatric disturbance may reduce the subsequent burden on the criminal justice system.”

Yet, whether conducting or interpreting research, the distinction between association and causation is of critical importance. Rutter, Kreppner, and O'Connor (2001) distinguish between risk indicators and risk mechanisms in developmental psychopathology, noting that, "Many variables show a statistically significant association with psychopathology, not because they represent a risk process as such, but because they predispose individuals to other experiences that actually mediate the risk" (p. 14). From the psychopathology perspective, a variable might be described as a risk factor if it fell within a broader model of circumstances or characteristics that contributed to the likelihood of offending, either directly or indirectly, thus representing what Rutter et al. (2001) called a risk indicator. On the other hand, the RNR literature's definition of risk factors has been based on strong, direct statistical relationships. To date, results of metaanalyses have reliably yielded the same set of variables to the point that these have become known as the "Big Four," describing the variables that most strongly predict recidivism which, together with another four moderate predictors, comprise the "Central Eight" (Andrews \& Bonta, 2010b). Andrews and Bonta (2010b) conclude that psychopathology variables are minor risk factors because these variables add only very slightly to predictive models beyond the contribution of the central eight. The potential contribution of psychopathological variables is concluded to be of little practical significance in predicting future risk to reoffend. Thus it is possible that a mental health issue may be highly correlated with offending behavior but may not directly impact the likelihood of re-offense, which could lead to its description as a risk factor within a psychopathological framework but rejection as a risk factor by the RNR literature. 


\section{(3) The predictors studied}

Following from the different conceptualizations of risk, the selection of predictors also varies in research representing the two perspectives. In the RNR literature, the same variables that have emerged as predictors of offending in the meta-analytic research are reflected in RNRbased assessment batteries and serve as organizing principles by which to plan treatment. The RNR literature is primarily interested in identifying variables that have a direct impact on the likelihood of recidivism. Variables that have an indirect effect are of interest only insofar as they affect primary variables. Variables that do not have a strong relationship to recidivism are of little interest and may even be considered by RNR-oriented researchers to be distracters from the primary goal of rehabilitation and a poor use of resources. Variables that have shown the strongest effect in predicting recidivism have been captured in standardized assessment instruments such as the Level of Service Inventory-Revised (LSI-R, Andrews \& Bonta, 1995) and its youth counterpart, the Youth Level of Service/Case Management Inventory (YLS/CMI, Hoge \& Andrews, 2011). Many RNR-informed researchers have used this standardized set of predictors, which has led to considerable consistency across researchers in the variables studied.

In contrast, in the psychopathology-based literature the selected variables reflect the clinical focus of this field. Accordingly, research has measured whether a range of mental health diagnoses can be used to predict outcomes for offenders (Vermeiren et al., 2002; Plattner et al., 2009). Several studies have also examined mental health in terms of self-reported symptomatology (i.e., Foster, Qaseem, \& Connor, 2004; Hartinger-Saunders et al., 2011). Selfreports may not necessarily reflect illness at diagnostic thresholds, which may yield different estimated rates of mental disorder versus clinician-diagnosis and, in turn, influence interpretations of the nature and scope of the mental health burden. Examples of other clinical 
variables that have been used as predictors include history of repeated victimization (Chang et al., 2003), involvement in a specialized mental health diversion program (Cuellar, McReynolds, \& Wasserman, 2006), receipt of community-based mental health services (Foster et al., 2004), abuse history (Vermeiren et al., 2002), or measures of emotion regulation or cognitive flexibility (Pihet et al., 2012).

\section{(4) The outcomes of interest}

The vast majority of RNR literature is focused on recidivism as the major outcome variable in relation to which risk factors are defined. Literature modeled on the RNR perspective may include specific variants of recidivism such as risk for violent recidivism, time to first re-offense, or severity of re-offenses. The RNR literature also tends to use official reports of offending and judicial involvement (e.g., Andrews \& Dowden, 2006); this approach is quite conservative and may yield different estimates of offending behaviors than self-report measures (Kirk, 2006; Andrews \& Bonta, 2010). Other goals, such as participation in employment, may be intermediate targets because they are associated with lower rates of recidivism. RNR-oriented authors have argued that rehabilitation and the reduction of recidivism are the most appropriate targets for intervention in the justice system as a means to reduce the attendant social costs of criminal offending on both the offender and the community. Andrews and Bonta (2010) argue that if an intervention is to play a role in the justice system, then "demonstrating an effect on recidivism is vital (p. 455)," and in their meta-analytic work they required that included studies had measured recidivism following program completion.

Those studies grouped under the psychopathology perspective include a more heterogeneous set of outcomes: self-reported delinquency (e.g., Boots, Wareham, \& Weir, 2011; Pihet et al., 2012), rates of violence (e.g., Walters, 2011), rates of aggressive behavior (Fanning, 


\section{TSpace Research Repository}

tspace.library.utoronto.ca

Berman, Mohn, \& McCloskey, 2011; Hodgins \& Riaz, 2011), conduct symptoms, days in detention, or history of aggression (e.g., Crowley, Mikulich, MacDonald, Young, \& Zerbe, 1998). Studies also examine predictors of first-time involvement in the justice system, which is not typically captured in the RNR focus on $r e$-offending. Researchers may also be concerned with predicting a number of other negative outcomes. For youth in particular, the lens of developmental psychopathology may investigate how normal developmental trajectories are interrupted. For instance, Vermeiren (2003) argued that, "because psychiatric conditions interfere with academic, social, and familial functioning, the long-term effects of psychopathology in [adolescent-limited] offenders must be considered from a broader perspective than antisocial involvement alone" (p. 307). Thus, the two literatures may draw different conclusions about intervention targets and policy implications based on these differences in outcomes of interest.

It is important to note that many of these outcomes are conceptually similar and yet differ in crucial ways, particularly in the areas of delinquency, judicial involvement, and antisocial behavior. Risk factors are defined relationally (Kazdin et al., 1997), such that a group is defined as being at risk relative to a particular reference group. In predictions of risk, the reference group at hand should first be compared to the reference group used in previous research. Delinquency and recidivism consider different reference samples (see Grieger \& Hosser, 2012). In particular, delinquency is typically considered across a community sample, assessing differences between those who engage in delinquency and those who do not: a between-subjects comparison. Recidivism, however, concerns a population that shares the common characteristic of having offended at least once: a within-subjects comparison. In this way, predictors of interest may differ according to the designated outcomes of interest, with some characteristics useful in distinguishing between groups who do and do not engage in delinquency, whereas those same 
characteristics may not be useful in distinguishing recidivists from non-recidivists. This would be expected, for example, if most delinquent youth possessed a quality that most non-delinquent youth did not; this characteristic may reliably distinguish between youth who are and are not delinquent but may not be useful in predicting which youth will recidivate if it is true for most youth in a group of offenders. In the case of psychopathology, recall that studies of prevalence rates have typically found that a large majority of offenders present with some level of symptomatology. The ubiquity of mental health problems in the general offender population may make this variable poorly suited to discriminating between likely recidivists and non-recidivists.

\section{(5) The timelines of interest}

Research from the two perspectives differs in the timelines of interest, both in terms of individuals' histories of offending and their mental health concerns. While the RNR literature declares a narrow interest in predicting and reducing re-offenses, the psychopathology literature includes a broad range of timelines: prospective studies of youth who have never been involved in the justice system (e.g., Bender, 2010; Cauffman, Scholle, Mulvey, \& Kelleher, 2005;

Copeland et al., 2007), youth currently in the system who may reoffend (e.g., Mulder, Brand, Bullens, \& van Marle, 2010; Shufelt \& Cocozza, 2006), and youth who have been involved with the justice system at any point, including historically (e.g., Pihet et al., 2012; Teplin, Welty, Abram, Dulcan, \& Washburn, 2012). Mental health issues may be relevant at any of these stages, reflecting pre-existing issues or emergent responses to the stresses of involvement in the justice system. As acknowledged in the broader developmental psychopathology literature, the factors associated with the first incidence of a negative outcome may differ from those factors that precipitate subsequent occurrences (Rutter \& Sroufe, 2000).

(6) The definition of mental health: Features versus disorders 


\section{TSpace Research Repository}

tspace.library.utoronto.ca

The two literatures differ in several respects in terms of how they label mental health-type concepts. The psychopathology literature has framed its discussion in terms of formal diagnostic labels, whereas the RNR literature speaks of formal diagnoses relatively infrequently and has instead spoken of particular features. Hence, psychopathology researchers may investigate Major Depressive Disorder or Dysthymia, Attention Deficit Hyperactivity Disorder (ADHD), and Substance Use Disorder, while RNR researchers use more general terms such as depression or personal emotional distress (Andrews \& Bonta, 2010b), impulsivity, or problematic patterns of substance use. These distinctions may seem trivial, yet they affect practice, theory, and dialogue.

In practice, the assessment demands differ for features- versus disorders-based approaches. The use of formal diagnoses offers the advantage of facilitating communication amongst professionals and informs mental health treatment planning. However, the assessment of disorders is restricted to professions with specialized mental health training and comprehensive mental health assessments can be time consuming (e.g., Abram, Paskar, Washburn, \& Teplin, 2008; Colins et al., 2012). The use of features, in contrast, offers certain practical advantages for use in a justice setting. The RNR approach, "is designed for use not only by sophisticated clinicians with formal graduate training but by the many correctional officers and probation officers who have face-to-face contact with their clients on a daily basis and who are in the best position to effect prosocial behavior change among their clients" (Wormith, Gendreau, \& Bonta, 2012, pp. 112-113). Accordingly, the observation of the presence or absence of a particular set of features can be accomplished by a much broader range of staff in the justice system and allows the use of the same set of predictors for all offenders when assessing risk, regardless of their mental health status (Bonta et al., 1998). The two approaches reflect different purposes for assessment, with a disorders-based approach best suited to mental health treatment planning and 
a features-based approach for the purposes of forensic risk assessment and case management. Because the RNR literature does not discuss mental health in terms of disorders, but rather in terms of features, it is not clear whether features contribute to risk for re-offense differentially when those features occur in the context of a mental health disorder than when they occur independently of mental health condition.

\section{(7) What is included in the category of mental health concerns}

Comparison of the major conclusions of these two literatures is vulnerable to reductionist generalizations about the role of 'mental health' in offending. As Douglas et al. (2009) observed, "In past research, mental illness was often considered a unitary, static construct... [whereas] finer gradations of conceptualization, to the symptom level if possible, are likely to provide more meaningful data ..." (p. 682). Hence we must consider what has been included under the umbrella of mental health before evaluating the comparability of their conclusions.

The psychopathology literature has included a much broader range of concerns than the RNR literature in its definition of mental health, generally including any disorder from the Diagnostic and Statistical Manual of Mental Disorders (currently in its fifth edition, DSM-5, American Psychiatric Association, 2013). In contrast, in the RNR approach features associated with offending outcomes are classified as risk factors and are not included in discussions of mental health; consequently the range of disorders considered is narrower. Crucially, in the RNR discussion, salient features do not necessarily occur in the context of a symptom cluster meriting diagnosis; that is, they may or may not be associated with an underlying mental health condition. Thus, mental health may be related to risky features that are associated with recidivism, thereby explaining the association between mental health and offending outside of diagnostic categories. 
As a result, the psychopathology literature might identify some offenders as having mental health diagnoses where RNR sees risk variables.

In particular, the two literatures have taken different approaches to the major behavior, substance use, and impulse control disorders, such as Conduct Disorder (CD), Oppositional Defiant Disorder (ODD), and the Substance Use Disorders (SUDs). The psychopathology literature has tended to include all of these diagnoses within the broad category of mental health problems. In contrast, the RNR literature has examined significant features of these disorders. For example, a youth might present with a history of stealing, threatening others, physical aggression, and defiance of rules and authority figures. These features could be captured using the formal diagnostic label of conduct disorder, but in the RNR framework they are instead described as criminogenic needs.

With this narrower definition of mental health and for the purposes of the risk assessment framework of the RNR model, mental health conditions are categorized as responsivity considerations rather than risk factors based on the results of meta-analytic studies. For example, Bonta et al. (1998) found that mood disorders had no impact on odds of recidivism and that psychosis was negatively related. Hence, depression and anxiety have often been referenced as possible responsivity considerations alongside possibly 'severe' forms of mental illness (Bonta, 1995; Kennedy \& Serin, 1997). Andrews and Bonta (2010) describe these as personal emotional distress/psychopathology variables, avoiding diagnostic labels. In sum, while comparison of the features and disorders-based approaches bridges some of the divide, these definitional differences limit comparison of findings from the two literatures.

\section{Areas of Disagreement}




\section{TSpace Research Repository}

tspace.library.utoronto.ca

These goals help to contextualize how authors may have conceptualized the mandate of their research and accordingly the scope of the conclusions drawn. However, the specific goal of reduced recidivism has been associated with significant conflict between the psychopathology and RNR-informed literatures. This difference in conceptualization emerges at multiple points: in the underlying models of the relationship, choice of predictors, empirical findings, dialogue between the literatures, and conclusions and implications drawn.

In essence, the apparent disagreement between the two approaches lies in the implicit perspective of the psychopathology literature that seems to posit a direct relationship between mental health needs and offending, contrasted against the RNR framework, which states that mental health, as defined within the framework, is not a direct risk factor for offending. The very implicitness of the psychopathology perspective is itself problematic because it is open to varying interpretations. For example, it is entirely possible that a significant number of psychopathology-oriented researchers who have discussed mental health as a risk for judicial involvement in general and recidivism in particular would not agree with the possible implications that individuals with mental illness are more dangerous or should be given more restrictive sentences. Rather, the intention seems often to advocate for more services for those with mental health problems. Researchers may also intend to draw attention to the higher number of disadvantageous social and contextual risk indicators amongst those with mental health problems rather than positing a direct, causal relationship. However, we cannot be sure of this set of assumptions unless they are clearly stated.

The next area of disagreement between the two literatures is more evident, and concerns the types and combinations of predictors chosen. In the psychopathology literature, the selection of clinical variables as predictors suggests that researchers expect that they in some way might 


\section{TSpace Research Repository}

tspace.library.utoronto.ca

reliably contribute to and therefore be predictive of offending behavior. However, many RNRoriented researchers have raised concerns about the conclusions reached by studies that include exclusively clinical predictors of recidivism and correspondingly treat mental disorders as a risk factor for reoffending (e.g., Grieger \& Hosser, 2012). In a recent review of the literature on programs developed for use with mentally-disordered adult offenders, Skeem et al. (2011) observed that these programs extended techniques that have been shown to positively affect clinical outcomes, such as levels of symptomatology, rather than criminal outcomes. There is little research written from the psychopathology perspective that has examined the predictive validity of these clinical variables alongside other criminological predictors.

Walters (2011) observed that the paucity of studies using both clinical and criminal predictors limits our ability to understand the relative contribution of these different types of variables and their possible roles in causal pathways to offending, re-offending, and other problematic outcomes, and whether clinical variables contribute over and above the predictive power of other risk variables. He concluded that further research was needed, "using a range of both psychiatric and criminologic mediators" (p.195). Indeed, this is the major criticism leveled by the RNR literature, which has found that clinical variables cease to contribute to the prediction of recidivism when examined in a model that includes other, more potent predictors. For example, Bonta et al. (1998) found that clinical variables associated with mental health status and treatment were not strong predictors of new offenses in general, or of new violent offenses. Rather, these were best predicted by non-clinical variables now known as criminogenic needs. Despite these arguments having been made for many years, many studies have been published that include only clinical predictors without a rationale offered in response to these criticisms. 


\section{TSpace Research Repository}

tspace.library.utoronto.ca

These differences in the underlying models, approach to research, and, consequently, reported findings, have contributed to conflicting perceptions of the problem. On the one hand, the high prevalence rate of mental health concerns in justice-involved populations has created a sense of urgency, particularly on the part of frontline workers and policymakers, around finding a solution for better management of these problems. Cuellar et al. (2006, p. 198) state, "The expansion of mental health diversion programs reflects an increasingly popular view that there is a causal relationship between youth mental disorders and crime. Consequently, for youth whose criminality reflects an underlying mental disorder, it also may be treatable.” At the very least, it has been commented that, "the exact contribution of psychopathology on reoffending is not clear, with few studies available and controversial results" (Plattner et al., 2009, p.400).

On the other hand, in the RNR literature, the issue is presented as having been largely settled; mental health disorders (within the definition discussed above) are not risk factors for offending but responsivity variables. Unfortunately, responsivity variables have received little empirical attention in the RNR literature in comparison to risk and need variables, and so this classification of mental health variables contributes little clarification as to their role, either in terms of risk assessment or rehabilitative programming ${ }^{2}$; this is especially unfortunate given the current level of popular interest. There is a growing number of RNR-based researchers who are examining issues around model implementation in order to improve rehabilitative programming in real-world settings (e.g., Bonta, Rugge, Scott, Bourgon, \& Yessine, 2008; Bourgon, Bonta, Rugge, Scott, \& Yessine, 2010; Eno Louden, Skeem, Camp, Vidal, \& Peterson, 2012; Haqanee, Peterson-Badali, \& Skilling, in press; Luong \& Wormith, 2011; Peterson-Badali \& Skilling, in press), which may provide a useful context for investigations into management of mental health problems amongst offenders. 


\section{TSpace Research Repository}

tspace.library.utoronto.ca

\section{Areas of Concordance}

There are also areas of substantial agreement between the two literatures once they are interpreted through the lens of their respective terminology, methodology, and goals. Both literatures stand in opposition to the view that "nothing works" to rehabilitate offenders. As Latessa et al. (2002) noted, programs focused on punishment over effective intervention have little basis in evidence. Although there are differences in the proposed targets for intervention, there is a shared interest in providing treatment to the individual offender in order to ameliorate his or her outcomes. Similarly, both literatures have an interest in increasing screening and assessment and both advocate caution about the possibly iatrogenic effects of custodial settings. Finally, both literatures generally suggest that low severity offenders should be minimally processed by the justice system. In the psychopathology literature, this is seen in the promotion of diversion, while the risk principle in the RNR literature suggests that high intensity intervention and incarceration be reserved for high risk offenders (Andrews \& Bonta, 2010b).

There is also substantive agreement in the findings and conceptualization of a number of problem areas when the broad label of "mental health" is deconstructed to examine specific disorders. The psychopathology literature has consistently found CD (or ODD) to be associated with offending (e.g., Vermeiren et al., 2002) and the RNR literature captures many of the diagnostic criteria for these disorders as risk variables (e.g., within the Personality/ Behavior and Attitudes criminogenic need domains). Much of the psychopathology literature has also associated SUDs with offending and the RNR literature likewise identifies problematic substance use behaviors as risk variables (e.g., Dowden \& Brown, 2002). Results concerning ADHD in the psychopathology literature are mixed, with both support for an association with offending (Gordon, Diehl, \& Anderson, 2012), and no association (Crowley et al., 1998; Grieger \& Hosser, 


\section{TSpace Research Repository}

tspace.library.utoronto.ca

2012). Vermeiren et al. (2002) noted that ADHD was so often comorbid with CD that it was difficult to discern whether ADHD explained any unique variance. The RNR literature instead focuses specifically on short attention span and poor frustration tolerance as risk variables.

Family variables have also been identified in both literatures as risky for offending, including family dysfunction, low parental warmth, low supervision, and family criminality (e.g., Andrews \& Bonta, 2010a; Cottle et al., 2001; Mulder et al., 2010; Gorman-Smith et al., 1998). Both literatures also identify measures of criminal history as risk factors. In the RNR literature, this is defined in terms of prior and current offenses, including history of detention or parole/ probation. In the psychopathology literature this is captured as number of days in detention, prior offenses, age at first incarceration (e.g., Plattner et al., 2009), peak aggressive incident, etc.; findings vary according to the exact variable used but it is evident that they share a common attempt to quantify the severity of previous offending in order to predict future outcomes.

In addition to identified risk factors, the two literatures also agree on several substantive treatment targets. The RNR literature has been firmly focused on recidivism as an overall outcome, as discussed, but the treatment of criminogenic needs is identified as the means by which the likelihood of recidivism is reduced. Accordingly, from an RNR perspective, variables such as impulsivity, involvement in prosocial activities, employment, family functioning, substance use, and hostile attributions are all possible targets for intervention as criminogenic needs; all of these areas might also be identified as treatment targets in a clinical setting. The RNR approach would target these areas to reduce the likelihood of subsequent offending while the psychopathology approach would target these areas to improve general functioning and adjustment. While the formulation of the treatment goals might be somewhat different, the fact remains that several possible treatment targets are shared by these two approaches. Indeed, 
treatment approaches such as Functional Family Therapy (FFT; Alexander, Waldron, Robbins, \& Neeb, 2013) and Multisystemic Therapy (MST; Henggeler, Melton, \& Smith, 1992) have effectively targeted criminal and delinquent behaviors with comprehensive treatment models that include other clinical targets, notably family functioning, relationships and communication.

Important contributions have been made by researchers who have integrated clinical and rehabilitation perspectives, advocating for the assessment and treatment of both mental health and criminogenic-type variables (e.g., the MacArthur Violence Risk Assessment Study; Mulvey et al., 2001), albeit not necessarily within the context of a formal rehabilitation perspective such as RNR. This research has generally supported the RNR assertion that criminogenic needs must be treated to reduce the likelihood of recidivism, but has also pointed to the as-yet unresolved question of the nature of the relationship between high rates of mental health problems and criminogenic need (Schubert, Mulvey \& Glasheen, 2011).

\section{Concluding Thoughts Regarding Divergent Goals and General Prescriptions for Research}

We have suggested that the apparent conflict between the psychopathology and RNR literatures reflects different fundamental goals. The RNR model was designed to promote rehabilitation and reduce reoffending. It is thus heavily focused on actuarial prediction of recidivism, treatment planning and service provision to reduce offending, and evidence-based guidelines on interventions and correctional practices. The psychopathology literature is an extension of the clinical literature to a specialized population - offenders - and thus retains its primary focus on provision of appropriate clinical services for mental health problems. This overarching goal includes describing prevalence in order to provide sufficient services, describing the clinical presentation of disorders and comorbidities for these individuals, informing formulation, and clinical service planning and service provision. 


\section{TSpace Research Repository}

tspace.library.utoronto.ca

Interpretation of any literature should be made within the parameters of its stated goals. Goals direct research design and selection of outcome measures, and concepts of risk are defined in relation to specific outcomes (Kazdin et al., 1997). The RNR framework explicitly aimed to address recidivism from its first formulation. It is less clear, however, how the investigation of recidivism aligns with the goals and focus of the psychopathology literature. Research that is expressly interested in how the mental health needs of offenders might interact with their risk of reoffending should be attentive to the existing research in the area by incorporating established criminogenic predictors. Studies examining psychopathology predictors alone are poorly suited to a stated goal of reduced recidivism. Given their influence on study scope and design, goals ought to be more carefully defined in research reports. The rationale for the choice of outcome measures should be clearly provided and conclusions should be offered with circumspection, in line with study design. The critical consumer of research must consider under what circumstances the literature is applicable.

The literature would also benefit from clearer labeling of the population of interest, with particular attention paid to defining the seriousness of offending history and of mental health concerns. As an example, Cuellar et al. (2006, p. 198) state that "(a)ll too often, people are misdiagnosed or not diagnosed with the root problem of mental illnesses. It is important to keep adults and youth with serious mental illnesses who are not criminals out of the criminal justice system..." This argument is related primarily to individuals who have committed offenses of low severity but whose mental health needs are of high severity. In the RNR literature, the risk principle states that intervention should be reserved for 'high risk offenders': those who have many criminogenic risk factors and, usually, a considerable history of offending. The RNR literature also tends to discuss mental health in terms that suggest authors are focused on mental 
health issues of low severity (i.e., "vague emotional/ personal problems," Dowden \& Andrews, 1999; "personal emotional distress," Andrews \& Bonta, 2010b)." Where there is this mismatch in the primary mental health problems of the population of interest, it is predictably associated with different conclusions as to the importance of clinical or criminal needs.

\section{Directions for Research}

In addition to calls for greater general clarity in the research on mental health and offending, there is a need for a more integrated approach in which the findings of both the RNR and psychopathology literatures meaningfully inform ongoing research, practice, and policy. Ultimately, the goal ought to be effective, practicable, defensible evidence-based practice. While the apparent conflicts and theoretical and methodological differences in understanding of mental health amongst offenders have been noted for some time, there have been few attempts to explain these differences and suggest ways to move ahead in a more productive collaboration. The impoverished dialogue between these literatures hinders the contributions they can make to one another and, perhaps more importantly, to policy and practice. Authors in the psychopathology literature often seem unaware of the strong research base for models of rehabilitation that could vitally inform their investigations. The RNR literature appears to dismiss the work of psychopathology-oriented researchers because of this oversight, and perhaps the general lack of focus on outcomes related to offending, while little has been written from the RNR perspective to explain why rates of mental health problems (from a clinical definition) are so high or what might be done to manage this challenge facing the justice system. We propose four key areas with outstanding questions that might benefit from research that is informed by and integrates findings from these two approaches.

\section{(1) Mental Health as Responsivity}




\section{TSpace Research Repository}

tspace.library.utoronto.ca

In the psychopathology literature, the relationship between mental health and offending has typically been modeled in terms of direct effects, though - as noted - there is little support for this model in the general offender population. This relationship can be examined in terms of two related but distinct aspects of mental health: (1) symptoms and/or diagnoses and (2) the effects of treatment designed to ameliorate mental health problems. With respect to the former, symptoms and diagnoses are not more predictive of recidivism than established criminogenic predictors, although individuals with mental health problems may have more of these criminogenic needs than do individuals without mental health problems (Girard \& Wormith, 2004). Skeem et al. (2011) concluded that the relationship between mental illness and criminal behavior is one of moderated mediation wherein there is a direct relationship between mental health status and criminal behavior for a small group of mentally ill offenders but for others the association is fully mediated by criminogenic needs. This study is an important first step in this area of research and there remains much work to be done, especially with youthful offenders.

It also remains unclear whether treatment of mental health problems alongside treatment of criminogenic risk is more effective than treating criminogenic risk alone. Research examining the effects of mental health on offending must distinguish between the effects of mental health symptoms or the effects of mental health treatment on outcomes. Most research has examined either the effect of mental health treatment (especially psychopathology researchers) or the effect of criminogenic needs treatment (especially RNR) in isolation. Meta-analyses have shown that interventions based on clinical outcomes do not necessarily improve criminal outcomes (e.g., Lipsey, 1999; Skeem et al., 2011). The RNR literature has thus argued that intervention should address criminogenic needs regardless of mental health symptoms, although mental health may be targeted as a responsivity variable (Bonta, 1995). It is therefore important to ask the question: 
Does treatment of mental health problems moderate the response to intermediate outcomes (treatment success)? If so, does it then exert some indirect effect on recidivism? Such research would help clarify whether mental health functions as a responsivity variable by affecting the likelihood of success of treatment designed to reduce offending - in other words, by acting as a moderator variable. This research would expand the RNR literature and provide a platform for inclusion of psychopathology-informed research, by: (1) clarifying the contribution of responsivity variables and (2) demonstrating how mental health can be understood and integrated with criminally-focused interventions, and (3) demonstrating how responsivity variables more generally can be included in empirical work.

\section{(2) Unpacking Mental Health}

It is also important to continue research that unpacks the 'mental health' construct to examine with greater specificity the role played by different disorders or clusters of disorders. For example, the role played by internalizing disorders is unclear. Depression severity has not been shown to predict conduct problems or criminal outcomes at follow-up (Crowley et al., 1998, Vermeiren et al., 2002; but see Van Voorhis, Wright, Salisbury, \& Bauman, 2010). Anxiety has been associated with shorter time to recidivism, but depression and dysthymia may protect against further offending when comorbid with anxiety (specifically, GAD; Plattner et al., 2009). Elsewhere, however, offenders described as anxious and amenable to treatment have been found to benefit significantly more from treatment in terms of lower rates of recidivism (Andrews et al., 1990). It is unclear if differences such as these are accounted for by differing definitions, by an effect of treatment, or by differing attitudes around help-seeking, a known criminogenic need as documented in the RNR literature. If internalizing disorders are protective, is that mediated by improved treatment compliance, for example? Understanding the effects of 


\section{TSpace Research Repository}

tspace.library.utoronto.ca

different disorders is important for understanding prognosis and elucidating the possible treatment implications for both mental health treatment and for rehabilitative programming.

That being said, high rates of comorbidity make it difficult to determine the contributions of individual disorders. For example, since justice-involved youth with depression often also present with comorbid CD and SUDs, it is unclear whether depression contributes any incremental risk, is protective, or is in fact unrelated to offending for these youth. Thus, in addition to consideration of the role of individual symptoms or disorders, future research should examine frequently-occurring clusters of comorbid disorders.

In recent years increasing attention has also been paid to trauma and PTSD amongst offenders (i.e., Abram et al., 2004). The prevalence of trauma and its impact on functioning are potentially significant in part because the impulsivity and reactivity that are frequent behavioral problems amongst offenders may be sequelae of trauma (Ford, Chapman, Mack, \& Pearson, 2006; Greenwald, 2002). In addition to the need for greater specificity in future research, this example illustrates the need for research that addresses whether 'feature'- or disorder-based approaches to understanding offenders' needs differ in terms of their prediction of criminal outcomes. Questions include: How do implications for risk assessment and treatment planning differ if the features identified as criminogenic in the RNR framework occur in the context of a mental health disorder rather than on their own (i.e., unconnected with an underlying mental health problem)? Are interventions targeted to these criminogenic needs less effective when they occur in the context of a mental health diagnosis, suggesting a specific responsivity consideration for mental health treatment? Is a different intervention 'dosage' necessary to improve outcomes when these features exist on their own versus as part of a mental health diagnosis? Given that 
many offenders present with mental health needs as well as criminogenic needs, it would be helpful to establish ways in which treatment of these two areas could be complementary.

\section{(3) Mental Health in a Developmental Context}

The role of mental health issues is perhaps especially unclear for youth. Whereas much of the literature has examined adults with serious mental health problems, young offenders are less likely to have well-documented, major mental illness by virtue of developmental course. The types of disorders, their prevalence, and the clarity of diagnoses would be expected to differ for young offenders relative to adult offenders, and therefore dominant themes from the adult literature do not necessarily extend to understanding youth. Further, youth may show signs of emergent illness that are not yet clear in terms of etiology. Accordingly, research focused specifically on youth will benefit from clarity in defining the population, disorders and/or features of interest, amongst other parameters, and examination of specific constructs within mental health that may be more relevant for the youth population, with the goal of elucidating both the relationship to offending and the implications for intervention. Research to track longer term criminal and clinical outcomes for youth may help to clarify characteristics of different subgroups, i.e., those with persistent versus limited offending, and persistent versus limited mental health issues. Casswell et al. (2012) observed that, "It is now widely recognized that the most chronic and severe mental health problems begin in adolescence, with $75 \%$ of all mental illnesses emerging between 15 and 25 years." Research should examine the extent to which a given disorder, such as depression, functions similarly in youth and adult offenders.

Readers should consider how mental disorders are assessed in research reports given that many justice-involved youth have not previously received mental health services. In the justice setting certain challenges may complicate assessment more often than in community practice, as 


\section{TSpace Research Repository}

tspace.library.utoronto.ca

the difficulty in obtaining collateral reports may hamper diagnoses. For example, Colins et al. (2012) found that parental reports of ADHD and CD were predictive of several offending outcomes, whereas youth self-reported symptomatology was not predictive. Readers should consider the mode of assessment, whether based on self-report or on clinician diagnosis, and whether diagnostic conclusions limited by lack of collateral information, such as if parents were unwilling or unable to be involved in assessment. Specific signs or features of illness may be associated with problematic behaviour and even offending before any definitive diagnosis can be identified. This presents important policy implications, as Grisso (1999) observed that, "What some of us in the United States fear, however, is that adult courts will not be as consistent about identifying mental illnesses and intellectual disabilities among juveniles who are tried as adults, because their disabilities are either harder to identify or take different forms than those with which adult courts typically have had to deal (p. 144)."

It ought to be noted here that work with youth in the justice system entails a further consideration that may be less relevant to the adult system. That is, by virtue of youth's vulnerability and minor status, the state's assumption of some partial custody over them entails a duty of care. Hence there is an expectation that the state will attend not only to rehabilitative goals but also in some measure to youths' health, safety and development, including such needs as education and mental health. However, there exists a well-recognized tension in expecting the justice system, which is usually perceived as adversarial, to assume a therapeutic role (Grisso, 2008). It is suggested that the targeted outcomes be clearly articulated so that readers and policy makers may assess whether a program meets a given mandate, be that the provision of mental health services or the reduction of criminal offending. 
In addition, research is needed on the ways in which mental health issues interact with systems influences for young offenders, such as the level of supervision and monitoring for youth with mental health issues versus those without, compliance with treatment and conditions of probation, and the selection of intervention targets in treatment planning for young offenders with mental health issues (e.g., do probation officers target mental health over criminogenic needs? What are the effects of service availability?).

\section{(4) Gender and Mental Health}

Considerable research also remains to be done on the interaction between gender and mental health. A vigorous debate as to whether mental health needs contribute differentially for girls and women is underway (see Hubbard \& Matthews, 2008, for an excellent summary). Some scholars have argued that assessment and treatment need to be 'gender-specific', particularly because girls and women have different risks, needs, and experiences of the justice system (e.g., (Hannah-Moffat, 2004). RNR researchers have countered that the framework should be considered to be 'gender-neutral', working equally well for females as for males (e.g., Dowden \& Andrews, 1999), with gender treated as a responsivity variable (e.g., Rettinger \& Andrews, 2010). A major point of contention has been the role played by mental health, which some scholars have argued is a gender-specific risk factor (both proximal and distal) for girls' and women's offending. Extensive discussion of gender-based differences is beyond the scope of this paper, but in recent years there has been a significant argument made that mental health, and related issues such as trauma history, as well as criminogenic needs and offending trajectories, may be quite different for women than for men. Research on both youth and adults in the justice system must continue to investigate these important issues at the intersection of gender, mental health, and offending and rehabilitation. Further research is needed on female offenders, and 
general research should include reporting of possible differences in direct effects or moderating variables between male and female offenders.

\section{Implications for Policy and Practice}

Policymakers must consider the question of how best to respond to individuals with serious mental health issues who come into contact with the justice system but they must also consider how to respond to mental health problems in offenders more generally. Given the widespread prevalence of mental health problems in offending populations, it has been suggested that consideration of these needs should be standard practice in the justice system. For example, Fraser et al. (2009) suggest that mental health policy ought to acknowledge that prisons are a major, albeit less traditional, guardian of individuals with mental health needs and should provide services and a therapeutic milieu. Further, independent of their impact on reoffending, symptoms of untreated mental health problems can lead to difficulty in managing offenders (Drerup et al., 2008) and "may contribute to longer incarcerations if the individual is unable to qualify for earlier release through good behavior" (p. 127). Policymakers may also have a legal and ethical obligation to provide adequate care for those classed as vulnerable persons (e.g., youth) when the state has assumed some duty of care.

Many frontline workers identify mental health as one of their major challenges in practice (Haqanee et al., 2014; Mead \& Moseley, 2004; Penn, Esposito, Stein, Lacher-Katz, \& Spirito, 2005). Prevalence rates are high and problems are perceived to have a significant impact on individuals' functioning and responsiveness to services. Of equal import is that intervention programs target criminogenic factors. Intervention that does not address known predictors of offending threatens a return to the conclusion that "nothing works" to rehabilitate offenders. The choice of intervention must be guided by the available evidence and by the goals of the setting. It 
is crucial that policymakers be informed by the findings of both the psychopathology- and RNRbased literatures and that they critically consider the types of factors enumerated in the present paper when determining the applicability of those findings to their goals and mandate.

\section{Conclusion}

In conclusion, we urge a consistent effort amongst researchers to explicitly define their assumptions, goals and intended application in order to facilitate dialogue between these approaches and ultimately align policy and practice with the evidence base. Most importantly, we urge researchers and policymakers to remember that these differing approaches share a common goal to improve treatment for individual offenders and to improve the functioning of the system in order to improve outcomes for both individuals and society. The challenges of mental health problems in offending populations are complex but improved inter-professional dialogue and greater clarity in evaluating and reporting research will further our capacity to meet these challenges with humane and effective services. 


\section{References}

Abram, K. M., Paskar, L. D., Washburn, J. J., \& Teplin, L. A. (2008). Perceived barriers to mental health services among youths in detention. Journal of the American Academy of Child \& Adolescent Psychiatry, 47, 301-308. doi: $10.1097 / \mathrm{CHI} .0 \mathrm{~b} 013 \mathrm{e} 318160 \mathrm{~b} 3 \mathrm{bb}$

Abram, K. M., Teplin, L. A., Charles, D. R., Longworth, S. L., McClelland, G. M., \& Dulcan, M. K. (2004). Posttraumatic stress disorder and trauma in youth in juvenile detention. Archives of General Psychiatry, 61, 403-410. doi: 10.1001/archpsyc.61.4.403

Abrantes, A. M., Hoffmann, N. G., \& Anton, R. (2005). Prevalence of co-occurring disorders among juveniles committed to detention centers. International Journal of Offender Therapy and Comparative Criminology, 49, 179-193. doi: $10.1177 / 0306624 X 04269673$

Abrantes, A. M., Hoffmann, N. G., Anton, R. P., \& Estroff, T. W. (2004). Identifying cooccurring disorders in juvenile justice populations. Youth Violence and Juvenile Justice, 2, 329-341. doi: $\underline{10.1177 / 1541204004267781}$

Alexander, J. F., Waldron, H. B., Robbins, M. S., \& Neeb, A. A. (2013). Functional family therapy for adolescent behavior problems. Washington, DC: American Psychological Association. doi:10.1037/14139-000

American Psychiatric Association. (2013). Diagnostic and statistical manual of mental disorders (5th ed.). Arlington, VA: American Psychiatric Publishing.

Andrews, D. A., \& Bonta, J. L. (1995). The Level of Service Inventory-Revised. Toronto, Canada: Multi-Health Systems.

Andrews, D. A., \& Bonta, J. (2010a). The psychology of criminal conduct (5th ed.). Cincinnati, OH, US: Anderson Publishing Co, Cincinnati, OH. 
Andrews, D. A., \& Bonta, J. (2010b). Rehabilitating criminal justice policy and practice. Psychology, Public Policy, and Law, 16, 39-55. doi: $10.1037 / \mathrm{a} 0018362$

Andrews, D. A., \& Dowden, C. (2006). Risk principle of case classification in correctional treatment: A meta-analytic investigation. International Journal of Offender Therapy and Comparative Criminology, 50, 88-100. doi: $10.1177 / 0306624 X 05282556$

Andrews, D. A., Bonta, J., \& Hoge, R. D. (1990). Classification for effective rehabilitation: Rediscovering psychology. Criminal Justice and Behavior, 17, 19-52. doi: $\underline{10.1177 / 0093854890017001004}$

Atkins, D. L., Pumariega, A. J., Rogers, K., Montgomery, L., Nybro, C., Jeffers, G., \& Sease, F. (1999). Mental health and incarcerated youth. I: Prevalence and nature of psychopathology. Journal of Child and Family Studies, 8, 193-204. doi: 10.1023/A:1022040018365

Bender, K. (2010). Why do some maltreated youth become juvenile offenders?: A call for further investigation and adaptation of youth services. Children and Youth Services Review, 32, 466-473. doi:10.1016/j.childyouth.2009.10.022

Bonta, J., Law, M., \& Hanson, K. (1998). The prediction of criminal and violent recidivism among mentally disordered offenders: A meta-analysis. Psychological Bulletin, 123, 123142. doi: $\underline{10.1037 / 0033-2909.123 .2 .123}$

Bonta, J., Rugge, T., Scott, T., Bourgon, G., \& Yessine, A. K. (2008). Exploring the black box of community supervision. Journal of Offender Rehabilitation, 47, 248-270. doi:

\section{$\underline{10.1080 / 10509670802134085}$}

Boots, D. P., Wareham, J., \& Weir, H. (2011). Gendered perspectives on depression and antisocial behaviors: An extension of the failure model in adolescents. Criminal Justice and Behavior, 38, 63-84. doi: 10.1177/0093854810388504 
Bourgon, G., Bonta, J., Rugge, T., Scott, T., \& Yessine, A. K. (2010). The role of program design, implementation, and evaluation in evidence-based "real world" community supervision. Federal Probation, 74, 2-15.

Calhoun, A.D., \& Clark-Jones, F. (1998). Theoretical frameworks: Developmental psychopathology, the public health approach to violence, and the cycle of violence. Pediatric Clinics of North America, 45, 281 - 291. doi: 10.1016/S0031-3955(05)70005-5

Casswell, M., French, P., \& Rogers, A. (2012). Distress, defiance or adaptation? A review paper of at-risk mental health states in young offenders. Early Intervention in Psychiatry, 6, 219228. doi: $\underline{10.1111 / \mathrm{j} .1751-7893.2012 .00344 . \mathrm{X}}$

Cauffman, E., Scholle, S. H., Mulvey, E., \& Kelleher, K. J. (2005). Predicting first time involvement in the juvenile justice system among emotionally disturbed youth receiving mental health services. Psychological Services, 2, 28-38. doi:10.1037/1541-1559.2.1.28

Cesaroni, C., \& Peterson-Badali, M. (2013). The importance of institutional culture to the adjustment of incarcerated youth and young adults. Canadian Journal of Criminology and Criminal Justice, 55(4), 563-575. doi: 10.3138/cjccj.2012.ES04

Chang, J. J., Chen, J. J., \& Brownson, R. C. (2003). The role of repeat victimization in adolescent delinquent behaviors and recidivism. Journal of Adolescent Health, 32, 272-280. doi: $\underline{10.1016 / \mathrm{S} 1054-139 \mathrm{X}(02) 00564-5}$

Chitsabesan, P., \& Bailey, S. (2006). Mental health, educational and social needs of young offenders in custody and in the community. Current Opinion in Psychiatry, 19, 355-360. doi: 10.1097/01.yco.0000228753.87613.01

Colins, O., Vermeiren, R., Vahl, P., Markus, M., Broekaert, E., \& Doreleijers, T. (2012). Parentreported attention-deficit hyperactivity disorder and subtypes of conduct disorder as risk 
factor of recidivism in detained male adolescents. European Psychiatry, 27, 329-334. doi: 10.1016/j.eurpsy.2011.01.001

Copeland, W. E., Miller-Johnson, S., Keeler, G., Angold, A., \& Costello, E. (2007). Childhood psychiatric disorders and young adult crime: A prospective, population-based study. The American Journal of Psychiatry, 164, 1668-1675. doi:10.1176/appi.ajp.2007.06122026

Cottle, C. C., Lee, R. J., \& Heilbrun, K. (2001). The prediction of criminal recidivism in juveniles: A meta-analysis. Criminal Justice and Behavior, 28, 367-394.

Crowley, T. J., Mikulich, S. K., MacDonald, M., Young, S. E., \& Zerbe, G. O. (1998).

Substance-dependent, conduct-disordered adolescent males: Severity of diagnosis predicts 2-year outcome. Drug and Alcohol Dependence, 49, 225-237. doi: 10.1016/S0376-

\section{$\underline{8716(98) 00016-7}$}

Cuellar, A. E., McReynolds, L. S., \& Wasserman, G. A. (2006). A cure for crime: Can mental health treatment diversion reduce crime among youth? Journal of Policy Analysis and Management, 25, 197-214. doi: 10.1002/pam.20162

Douglas, K. S., Guy, L. S., \& Hart, S. D. (2009). Psychosis as a risk factor for violence to others: A meta-analysis. Psychological Bulletin, 135(5), 679-706. doi: 10.1037/a0016311

Dowden, C., \& Andrews, D. A. (1999). What works for female offenders: A meta-analytic review. Crime \& Delinquency, 45, 438-452. doi: $10.1177 / 0011128799045004002$

Dowden, C., \& Brown, S. L. (2002). The role of substance abuse factors in predicting recidivism: A meta-analysis. Psychology, Crime \& Law, 8, 243-264. doi: $\underline{10.1080 / 10683160208401818}$ 
Drerup, L. C., Croysdale, A., \& Hoffmann, N. G. (2008). Patterns of behavioral health conditions among adolescents in a juvenile justice system. Professional Psychology: Research and Practice, 39, 122-128. doi: 10.1037/0735-7028.39.2.122

Eno Louden, J., Skeem, J. L., Camp, J., Vidal, S., \& Peterson, J. (2012). Supervision practices in specialty mental health probation: What happens in officer-probationer meetings? Law and Human Behavior, 36, 109-119. doi: 10.1037/h0093961

Erickson, C. D. (2012). Using systems of care to reduce incarceration of youth with serious mental illness. American Journal of Community Psychology, 49, 404-416. doi: $\underline{10.1007 / \mathrm{s} 10464-011-9484-4}$

Fanning, J. R., Berman, M. E., Mohn, R. S., \& McCloskey, M. S. (2011). Perceived threat mediates the relationship between psychosis proneness and aggressive behavior. Psychiatry Research, 186, 210-218. doi: 10.1016/j.psychres.2010.09.010

Fazel, S., Doll, H., \& Långström, N. (2008). Mental disorders among adolescents in juvenile detention and correctional facilities: A systematic review and metaregression analysis of 25 surveys. Journal of the American Academy of Child \& Adolescent Psychiatry, 47, 10101019. doi:10.1097/CHI.0b013e31817eecf3

Ford, J. D., Chapman, J. F., Mack, M., \& Pearson, G. (2006). Pathways from traumatic child victimization to delinquency: Implications for juvenile and permanency court proceedings and decisions. Juvenile and Family Court Journal, 57, 13-26. doi: 10.1111/j.17556988.2006.tb00111.x

Foster, E. M., Qaseem, A., \& Connor, T. (2004). Can better mental health services reduce the risk of juvenile justice system involvement? American Journal of Public Health, 94, 859-65. 
Gendreau, P., Little, T., \& Goggin, C. (1996). A meta-analysis of the predictors of adult offender recidivism: What works! Criminology, 34, 575-607.

Girard, L., \& Wormith, J. S. (2004). The predictive validity of the Level of Service InventoryOntario revision on general and violent recidivism among various offender groups. Criminal Justice and Behavior, 31(2), 150-181. doi: 10.1177/0093854803261335

Goldstein, N. E. S., Olubadewo, O., Redding, R. E., \& Lexcen, F. J. (2005). Mental health disorders: The neglected risk factor in juvenile delinquency. In K. Heilbrun, N.E.S. Goldstein, \& R.E. Redding (Eds.), Juvenile delinquency: Prevention, assessment, and intervention (pp. 85-110). New York, NY, US: Oxford University Press, 2005.

Gordon, J. A., Diehl, R. L., \& Anderson, L. (2012). Does ADHD matter? examining attention deficit and hyperactivity disorder on the likelihood of recidivism among detained youth. Journal of Offender Rehabilitation, 51, 497-518. doi: 10.1080/10509674.2012.702714

Gorman-Smith, D., Tolan, P. H., Loeber, R., \& Henry, D. B. (1998). Relation of family problems to patterns of delinquent involvement among urban youth. Journal of Abnormal Child Psychology, 26, 319-333. doi: 10.1023/A:1021995621302

Greenwald, R. (2002). The role of trauma in conduct disorder. Journal of Aggression, Maltreatment and Trauma, 6, 5-23. doi: 10.1300/J146v06n01_02

Grieger, L., \& Hosser, D. (2012). Attention deficit hyperactivity disorder does not predict criminal recidivism in young adult offenders: Results from a prospective study. International Journal of Law and Psychiatry, 35, 27-34. doi: 10.1016/j.ijlp.2011.11.005

Grisso, T. (2008). Adolescent offenders with mental disorders. The Future of Children, 18, 143164. 
Grisso, T. (1999). Juvenile offenders and mental illness. Psychiatry, Psychology and Law, 6, $143-152$.

Grudzinskas, A. J., Clayfield, J. C., Roy-Bujnowski, K., Fisher, W. H., \& Richardson, M. H. (2005). Integrating the criminal justice system into mental health service delivery: The worcester diversion experience. Behavioral Sciences \& the Law, 23, 277-293. doi:

\section{$\underline{10.1002 / \mathrm{bsl} .648}$}

Hannah-Moffat, K. (2004). V. gendering risk at what cost: Negotiations of gender and risk in canadian women's prisons. Feminism \& Psychology, 14, 243-249. doi: 10.1177/0959$\underline{353504042178}$

Haqanee, Z., Peterson-Badali, M., \& Skilling, T.A. (In press). Making 'What Works' Work: Examining Probation Officers' Experiences Addressing the Criminogenic Needs of Juvenile Offenders. Journal of Offender Rehabilitation.

Hartford, K., Carey, R., \& Mendonca, J. (2006). Pre-arrest diversion of people with mental illness: Literature review and international survey. Behavioral Sciences \& the Law, 24, 845856. doi: $\underline{10.1002 / b s 1.738}$

Hartinger-Saunders, R.M., Rittner, B., Wierczorek, W., Nochajski, T., Rine, C. M., \& Welte, J. (2011). Victimization, psychological distress and subsequent offending among youth. Children and Youth Service Review, 33, 2375-2385. doi:10.1016/j.childyouth.2011.08.009

Henggeler, S. W., Melton, G. B., \& Smith, L. A. (1992). Family preservation using multisystemic therapy: An effective alternative to incarcerating serious juvenile offenders. Journal of Consulting and Clinical Psychology, 60, 953-961. doi:10.1037/0022006X.60.6.953 
Hodgins, S., \& Riaz, M. (2011). Violence and phases of illness: Differential risk and predictors. European Psychiatry, 26, 518-524. doi: 10.1016/j.eurpsy.2010.09.006

Hoge, R. D., \& Andrews, D. A. (2011). Youth Level of Service/Case Management Inventory 2.0. Toronto, ON: Multi-Health Systems Inc.

Hubbard, D. J., \& Matthews, B. (2008). Reconciling the differences between the "genderresponsive" and the "what works" literatures to improve services for girls. Crime \& Delinquency, 54, 225-258. doi: $\underline{10.1177 / 0011128706296733}$

Kazdin, A. E., Kraemer, H. C., Kessler, R. C., Kupfer, D. J., \& Offord, D. R. (1997). Contributions of risk-factor research to developmental psychopathology. Clinical Psychology Review, 17, 375-406. doi: 10.1016/S0272-7358(97)00012-3

Kennedy, S. \& Serin, R.C. (1997). Treatment responsivity: Contributing to effective correctional programming. International Community Corrections Association Journal, 7, 46-52.

Kenny, D. T., Lennings, C. J., \& Nelson, P. K. (2007). The mental health of young offenders serving orders in the community: Implications for rehabilitation. Journal of Offender Rehabilitation, 45, 123-148. doi: 10.1300/J076v45n01_10

Kirk, D.S. (2006). Examining the divergence across self-report and official data sources on inferences about the adolescent life-course of crime. Journal of Quantitative Criminology, 22, 107-129. doi: 10.1007/s10940-006-9004-0.

Latessa, E. J., Cullen, F. T., \& Gendreau, P. (2002). Beyond correctional quackeryProfessionalism and the possibility of effective treatment. Federal Probation, 66 (2), 43 49.

Liebling, A. and Maruna, S. (Eds). (2005). The Effects of Imprisonment. Cullompton, Devon: Willan Publishing. 
Lipsey, M. W. (1999). Can intervention rehabilitate serious delinquents? Annals of the American Academy of Political and Social Science, 564, 142-166.

Lipsey, M. W., \& Derzon, J. H. (1998). Predictors of violent or serious delinquency in adolescence and early adulthood: A synthesis of longitudinal research. Serious \& violent juvenile offenders: Risk factors and successful interventions (pp. 86-105). Thousand Oaks, CA, US: Sage Publications, Inc, Thousand Oaks, CA.

Luong, D., \& Wormith, J. S. (2011). Applying risk/need assessment to probation practice and its impact on the recidivism of young offenders. Criminal Justice and Behavior, 38, 1177 1199. doi: $\underline{10.1177 / 0093854811421596}$

Mallett, C. A. (2013). Youthful offending and delinquency: The comorbid impact of maltreatment, mental health problems, and learning disabilities. Child \& Adolescent Social Work Journal, doi:10.1007/s10560-013-0323-3.

Mead, D., \& Moseley, L. (2004). Awareness of the health needs of prisoners. Journal of Research in Nursing, 9, 194-207. doi: 10.1177/136140960400900305

Monahan, J., Steadman, H. J., Silver, E.; Appelbaum, P. S.; Robbins, P. C.; Mulvey, E. P., ... \& Banks, S. (2001). Rethinking risk assessment: The MacArthur study of mental disorder and violence. New York: Oxford University Press.

Mulder, E., Brand, E., Bullens, R., \& Van Marle, H. (2010). A classification of risk factors in serious juvenile offenders and the relation between patterns of risk factors and recidivism. Criminal Behaviour and Mental Health, 20, 23-28. doi: 10.1002/cbm.754

Penn, J. V., Esposito, C., Stein, L. A. R., Lacher-Katz, M., \& Spirito, A. (2005). Juvenile correctional workers' perceptions of suicide risk factors and mental health issues of 
incarcerated juveniles. Journal of Correctional Health Care, 11, 333-346. doi:

\section{$\underline{10.1177 / 107834580401100403}$}

Perkins, D. F., \& Borden, L. M. (2003). Positive behaviors, problem behaviors, and resiliency in adolescence. Hoboken, NJ, US: John Wiley \& Sons Inc, Hoboken, NJ.

Peterson-Badali, M., \& Skilling, T. (In press). Examining implementation of risk assessment in case management for youth in the justice system. Criminal Justice and Behavior.

Pihet, S., Combremont, M., Suter, M., \& Stephan, P. (2012). Cognitive and emotional deficits associated with minor and serious delinquency in high-risk adolescents. Psychiatry, Psychology and Law, 19(3), 427-438. doi: 10.1080/13218719.2011.598634

Plattner, B., Steiner, H., The, S. S. L., Kraemer, H. C., Bauer, S. M., Kindler, J., . . Feucht, M. (2009). Sex-specific predictors of criminal recidivism in a representative sample of incarcerated youth. Comprehensive Psychiatry, 50, 400-407. doi:

\section{$\underline{10.1016 / j . c o m p p s y c h .2008 .09 .014}$}

Rettinger, L. J., \& Andrews, D. A. (2010). General risk and need, gender specificity, and the recidivism of female offenders. Criminal Justice and Behavior, 37, 29.

Robertson, P., Barnao, M., \& Ward, T. (2011). Rehabilitation frameworks in forensic mental health. Aggression and Violent Behavior, 16, 472-484. doi:10.1016/j.avb.2011.03.003

Rutter, M. L., Kreppner, J. M., \& O'Connor, T. G. (2001). Specificity and heterogeneity in children's responses to profound institutional privation. The British Journal of Psychiatry, 179, 97-103. doi: 10.1192/bjp.179.2.97

Rutter, M., \& Sroufe, L. A. (2000). Developmental psychopathology: Concepts and challenges. Development and Psychopathology, 12, 265-296. doi: 10.1017/S0954579400003023 
Schubert, C. A., Mulvey, E. P., \& Glasheen, C. (2011). Influence of mental health and substance use problems and criminogenic risk on outcomes in serious juvenile offenders. Journal of the American Academy of Child \& Adolescent Psychiatry, 50, 925-937. doi:

10.1016/j.jaac.2011.06.006

Shufelt, J.S. \& Cocozza, J.C. (2006). Youth with mental health disorders in the juvenile justice system: Results from a multi-state, multi-system prevalence study. Delmar, NY: National Center for Mental Health and Juvenile Justice.

Skeem, J. L., Manchak, S., \& Peterson, J. K. (2011). Correctional policy for offenders with mental illness: Creating a new paradigm for recidivism reduction. Law and Human Behavior, 35, 110-126. doi: 10.1007/s10979-010-9223-7

Skeem, J., Manchak, S., Vidal, S., \& Hart, E. (2009, March). Probationers with mental disorder: What (really) works? Paper presented at the annual conference of the American Psychology - Law Society (AP-LS), San Antonio, TX. Retrieved from https://webfiles.uci.edu/skeem/Downloads files/ServicesMediation.pdf

Teplin, L. A. (1990). Detecting disorder: The treatment of mental illness among jail detainees. Journal of Consulting and Clinical Psychology, 58, 233-236. doi: 10.1037/0022$\underline{006 X .58 .2 .233}$

Teplin, L. A. (1994). Psychiatric and substance abuse disorders among male urban jail detainees. American Journal of Public Health, 84, 290-293. doi: 10.2105/AJPH.84.2.290

Teplin, L. A., Abram, K. M., McClelland, G. M., Dulcan, M. K., \& Mericle, A. A. (2002). Psychiatric disorders in youth in juvenile detention. Archives of General Psychiatry, 59, 1133-1143. doi: $10.1001 / \operatorname{archpsyc} .59 .12 .1133$ 
Teplin, L. A., Abram, K. M., McClelland, G. M., Washburn, J. J., \& Pikus, A. K. (2005).

Detecting mental disorder in juvenile detainees: Who receives services. American Journal of Public Health, 95, 1773-1780. doi: 10.2105/AJPH.2005.067819

Teplin, L. A., Welty, L. J., Abram, K. M., Dulcan, M. K., \& Washburn, J. J. (2012). Prevalence and persistence of psychiatric disorders in youth after detention: A prospective longitudinal study. JAMA Psychiatry, 69, 1031-1043.

Ulzen, T. P. M., \& Hamilton, H. (1998). The nature and characteristics of psychiatric comorbidity in incarcerated adolescents. The Canadian Journal of Psychiatry / La Revue Canadienne De Psychiatrie, 43, 57-63.

Unruh, D. K., Gau, J. M., \& Waintrup, M. G. (2009). An exploration of factors reducing recidivism rates of formerly incarcerated youth with disabilities participating in a re-entry intervention. Journal of Child and Family Studies, 18, 284-293. doi: 10.1007/s10826-008$\underline{9228-8}$

Van Voorhis, P., Wright, E. M., Salisbury, E., \& Bauman, A. (2010). Women's risk factors and their contributions to existing risk/needs assessment: The current status of a genderresponsive supplement. Criminal Justice and Behavior, 37, 261-288. doi: $\underline{10.1177 / 0093854809357442}$

Vermeiren, R. (2003). Psychopathology and delinquency in adolescents: A descriptive and developmental perspective. Clinical Psychology Review, 23, 277-318. doi: 10.1016/S0272$\underline{7358(02) 00227-1}$

Vermeiren, R., Jespers, I., \& Moffit, T. (2006). Mental health problems in juvenile justice populations. Child and Adolescent Psychiatric Clinics of North America, 15, 333-351. doi: $\underline{10.1016 / \text { j.chc. } 2005.11 .008}$ 
Vermeiren, R., Schwab-Stone, M., Ruchkin, V., De Clippele, A., \& Deboutte, D. (2002). Predicting recidivism in delinquent adolescents from psychological and psychiatric assessment. Comprehensive Psychiatry, 43, 142-149. doi: 10.1053/comp.2002.30809

Walters, G. D. (2011). Criminal thinking as a mediator of the mental illness-prison violence relationship: A path analytic study and causal mediation analysis. Psychological Services, 8 , 189-199. doi: $10.1037 / \mathrm{a} 0024684$

Ward, T., \& Stewart, C. (2003). Criminogenic needs and human needs: A theoretical model. Psychology, Crime \& Law, 9, 125-143. doi: 10.1080/1068316031000116247

Wasserman, G. A., McReynolds, L. S., Schwalbe, C. S., Keating, J. M., \& Jones, S. A. (2010). Psychiatric disorder, comorbidity, and suicidal behavior in juvenile justice youth. Criminal Justice and Behavior, 37, 1361-1376. doi: 10.1177/0093854810382751

Wierson, M., \& Forehand, R. (1995). Predicting recidivism in juvenile delinquents: The role of mental health diagnoses and the qualification of conclusion by race. Behaviour Research and Therapy, 33, 63-67. doi: 10.1016/0005-7967(94)E0001-Y

Winick, B. J., \& Wexler, D. B. (Eds.). (2003). Judging in a therapeutic key: Therapeutic Jurisprudence and the Courts. Durham, NC: Carolina Academic Press.

Wormith, J. S., Gendreau, P., \& Bonta, J. (2012). Deferring to clarity, parsimony, and evidence in reply to Ward, Yates, and Willis. Criminal Justice and Behavior, 39, 111-120. doi: $\underline{10.1177 / 0093854811426087}$ 


\section{Author Notes}

${ }^{1}$ We urge caution in the reporting of sources. In our review of the literature, we found several references to the notion that mental health is a risk factor for recidivism which, upon closer inspection, were not references to primary sources. As one example, in attempting to trace the source of a recent claim, we found the original finding was four sources (and more than thirty years) removed. Elsewhere, discussions of possible relationships are cited by subsequent authors with the same weight as empirical findings.

${ }^{2}$ Of what has been written, most concerns the notion of 'general' or 'external' responsivity, which pertains more to program or system characteristics associated with intervention effectiveness, rather than to specific responsivity, or characteristics of the individual offender, including mental health status. 